de las cartas. En él no solo pueden verse los movimientos entre los espacios públicos y privados, sino que se recogen distintos testimonios de mujeres que viajaban tanto por el interior como por el exterior del país. La autora se beneficia también de las fuentes arqueológicas, que le permiten ampliar la información aportada por las misivas objeto de estudio. El resultado es romper con el pensamiento tradicional reflejado en la literatura, en el que a la mujer romano-egipcia se la había relegado tan solo a un ámbito doméstico, y demostrar que tenía también un importante papel fuera de este. Finalmente, el capítulo IV, "El rol económico de las mujeres: situación, participación y gestión económica en las cartas privadas", versa sobre las actividades económicas, uno de los temas más recurrentes en las mismas. Un interesante apartado, relacionado, en parte, con el anterior, donde se muestra a mujeres a cargo de la gestión de propiedades y otras actividades económicas.

En definitiva, este libro de Amaia Goñi Zabalegui será una obra de referencia para los estudios del Egipto grecorromano en lengua castellana, no solo por la gran aportación de fuentes textuales, sino también por abrir el camino de los estudios de género en esta disciplina.

D.O.I.: 10.1344/Lectora2020.26.18

MARC ORRIOLS-LLONCH marc.orriols@uab.cat

Universitat Autònoma de Barcelona

\title{
Tornar a encantar el món. El feminisme i la política dels comuns
}

Silvia Federici

Traducció d'Aurora Ballester

Manresa, Tigre de Paper, 2019, 286 pp. ISBN: 978-84-16855-47-6

El 1917 Max Weber va parlar del "desencant del món”. A grans trets, assenyalava la desaparició de la religiositat a conseqüència de la racionalització produïda per les formes d'organització social derivades, sobretot, del progrés científic i tecnològic. Quasi un segle després, la pensadora Silvia Federici (1942) llançà un repte: tornar a encantar el món. Ho feia en un article que ara clou el seu darrer llibre, Re-enchanting the World: Feminism and the Politics of the Commons (2018), en versió al català d'Aurora Ballester per a Tigre de Paper.

L'edició recull articles publicats entre els noranta i el 2017. Està dividida en dues parts complementàries: la primera ofereix una anàlisi de les noves formes d'encerclament que han succeit els vells tancaments de terres, mentre que la segona aprofundeix en el comú com a realitat present en certes formes d'organització social. Voldria aprofitar aquestes ratlles per mostrar com, sense abandonar la seva aposta per 
una anàlisi sistèmica de base marxiana, Federici situa les lluites de les dones pels comuns al centre de la resistència contra les noves ofensives capitalistes. En particular, pel que fa a la seva capacitat d'imaginació política. El verb italià incantare prové del llatí canere ("cantar"). Aquest mot llatí no només fa al-lusió al fet de cantar o recitar una fórmula màgica, sinó que incorpora un vessant profètic ("predir"). En la proposta de l'avesada activista ressona aquest vincle: tot polititzant l'advertència de Weber, la interpreta com un bloqueig que impedeix que el malestar esdevingui acció transformadora. Sense destil.lar nostàlgia per temps remots, Federici insisteix a des-cobrir - a recuperar allò que ha romàs ocult- raons i lògiques diferents de les que imposa el sistema capitalista.

L'atenció als moviments impulsats per les dones és crucial a l'hora de fer aparèixer aquesta altra racionalitat, que "no només s’oposa a la injustícia social i econòmica sinó que ens reconnecta amb la natura i reinventa el que significa ser un ésser humà" (253). Entrevistada per la periodista Olga Rodríguez, la professora emèrita a la Universitat de Hofstra, a Nova York, emfatitzava que ella no explica pas les dones, n'aprèn. La inspiració per transformar el món prové de les lluites de les qui s'han trobat històricament al centre de la reproducció social, però també (o consegüentment) als marges del treball assalariat - fet que ha accentuat, i això és vital per l'autora, la seva relació de dependència amb els comuns de la natura.

Els articles escollits reprenen el fil de l'obra més coneguda de Federici-Caliban i la bruixa (2004)—: amb i contra Marx, argumenta que l'acumulació originària és un fenomen substancial i periòdic del capitalisme i defensa que els tancaments, lluny de beneficiar petits productors privats, tenen per objectiu la destrucció del terreny on arrela el poder proletari. A partir d'aquesta premissa la pensadora descriu un nou procés d'acumulació orquestrat pel Banc Mundial i el Fons Monetari Internacional: l'anomenada "crisi del deute" que es va produir quan la Reserva Federal dels Estats Units va augmentar el tipus d'interès del dòlar (1979) i els països del “Tercer Món” es van veure incapaços de tornar els seus préstecs. Per Federici, la subsegüent intervenció econòmica - en forma de "plans d'ajust estructural" d'aquest deute- ha erradicat moltes de les fites assolides per les lluites anticolonials i ha permès que les agències estrangeres s'apropiïn dels recursos de l'Àfrica i l'Amèrica Llatina. Aquest procés persegueix objectius similars a les formes de tancament que l'han precedit, i que l'escriptora coneix bé, com ara la colonització o l'expulsió de la pagesia de les terres comunals a l'Europa del segle XVI. L'estratègia consisteix a posar fi al control comunal dels mitjans de subsistència per destruir els drets consuetudinaris i les formes de vida autòctones. Això trasplanta els i les treballadores a un nou escenari en què esdevenen mà d'obra mòbil i migrant, és a dir, subjectes de precarietat laboral, desarrelament comunal i de màxima vulnerabilitat legal.

Però l'interès d'aquests articles no rau només en el fet d'inserir les relacions financeres actuals en un procés de tancament progressiu de terres, sinó en la seva 
capacitat per il-luminar-ne un aspecte essencial: la desarticulació del cos social per mitjà de "la imposició de diferents règims disciplinaris que produeixen una acumulació de 'diferències' i jerarquies” (39). Ras i curt: la destrucció dels comuns va més enllà de l'atac capitalista a un tipus de relació de propietat - que no concerneix un privat o l'Estat-; atempta contra les formes de relació i d'atenció establertes entre les persones que habiten una mateixa terra. En aquest sentit, l'impuls feminista per no separar allò personal del fet polític i per aplicar el principi del comú a l'organització de la reproducció social prefigura una comunitat regida pels principis de cooperació i corresponsabilitat. Aquesta reflexió - recorda Federici- beu de la seva experiència com a professora a Nigèria a principis dels vuitanta, de l'estudi dels moviments socials a Sud-amèrica i del contacte amb organitzacions de dones d'allà. Amb el record d'aquestes lluites, però també de moviments com l'estatunidenc Occupy, l'autora conclou que és el proletariat femení mundial qui -més sovint guiat per la necessitat que per la ideologia - resisteix arreu l'atac a la vida i ens crida, com l'eslògan feminista dels setanta, a reprendre-la des del primer terreny on es pot exercir l'autogovern: les tasques reproductives, la "zona zero de la revolució" (254). En definitiva, Federici no posa el focus en la destrucció del comú, sinó en la seva reconstrucció lluitant contra el privilegi en un combat que no separi el temps de la organització política revolucionària del de la reproducció del cos i de la memòria -que permet seguir el rastre d'una comunitat mai extingida del tot. Tornar a encantar el món és, avui, condició de possibilitat per decidir col-lectivament sobre el demà.

Andrea Pérez FernándeZ andreaperez@ub.edu

\title{
Revolución feminista y políticas de lo común frente a la extrema derecha
}

\author{
María Eugenia R. Palop
}

Barcelona, Icaria, 2019, 151 pp. ISBN: 978-84-9888-882-9

Dirigida a un público amplio, la colección Más Madera de Icaria ofrece textos breves que rehúyen del lenguaje académico o excesivamente técnico para tratar temas contemporáneos de una manera clara y amena, pero a la vez precisa. El volumen de la jurista, investigadora, articulista y, ahora eurodiputada por Podemos, María Eugenia R. Palop, tiene como objetivo echar luz sobre tres fenómenos contemporáneos que aquí se presentan como interrelacionados: el ascenso de movimientos políticos de extrema derecha en Europa y América, la nueva ola feminista global y el avance de las 